\section{Innovations in Extension from Malawi}

\author{
S.S. Snapp ${ }^{1}$
}

AdDITIONAL INDEX WORDS. collaboration, private and public sectors, participatory extension, transferring technology, southern Africa, new crop outreach

Summary. Extension services around the globe face increasingly limited financial support, yet rural populations require services, training and access to information. In sub-Saharan African countries the demands are particularly severe. Farmer to extension staff ratios are generally over 2000 to 1 and resource constraints are severe, which greatly restricts outreach efforts. Examples are presented of recent innovations from the southern Africa country of Malawi. These include collaboration across private and public institutions. Some extension agents have shifted from a transferring technology mode to a catalytic role where agents help link up diverse stakeholders, from farmers and researchers to potential buyers and input suppliers. Extension has helped farmers respond to new market opportunities, including a food colorant, the paprika pepper (Capsicum annuum), and a multi-use grain and vegetable, pigeon pea (Cajanus cajan). Product quality is critical for these markets and industry organizations have invested in training that involves government extension staff, private crop advisors and farmers. A collaborative team approach across industry, nongovernmental organizations and government services has facilitated farmer access to inputs, new cultivars and training in improved crop management and postharvest techniques. Many challenges remain, such as outreach to farmers located far from infrastructure and those with limited formal education or no experience with entrepreneurship. Extension must continue to reinvent itself to reach all farmers.

$\mathrm{E}$ xtension in southern Africa faces severe challenges of limited resources, insufficient staff and a massive clientele that requires technical

${ }^{1}$ Assistant professor of integrated crop management, Department of Horticulture, Michigan State University, East Lansing, MI 48824-1325; snapp@msu.edu. assistance. As extension attempts to reinvent itself in both the developing and developed worlds, this paper outlines a few examples of innovative outreach under very difficult conditions.

More than $80 \%$ of the population in Malawi is rural, engaged primarily in smallholder agriculture. Smallholders are the overwhelming majority of farmers in Malawi with an average farm size of $<1.5$ ha $(3.71$ acres) (Benson, 2002). In most arable areas, fallowing has almost disappeared as the population is now $>105$ people $/ \mathrm{km}^{2}$ (271.9 people $/ \mathrm{mile}^{2}$ ) and continuous production of crops has become the norm (Kumwenda et al., 1997). Corn (Zea mays) is the most important grain crop, grown as a monoculture or intercropped with grain legumes such as groundnut (Arachis bypogaea) and common bean (Phaseolus vulgaris) (Snapp et al., 2002b). The primary horticultural export crop is tobacco (Nicotiana tabacum) and a paprika dried product exported as a natural food colorant is an important, new income source for some smallholder farmers (Toomey et al., 2000).

Government extension in Malawi, as elsewhere, has the mandate to work with agricultural research services and reach millions of smallholder farmers. Yet inadequate training and staff mean that the information flow is often bottlenecked and technical innovations rarely reach the majority of farmers. The Malawi extension service is set up to have staff in every district of the country; however the ratio of clients to extension agents is greater than two thousand to one in most districts (Table 1). A survey of smallholder farmers in Kasungu (central Malawi) and Mangochi (southern Malawi) found that only $5 \%$ of farmers had ever received information from extension agents ( $S$. Snapp, unpublished data).

A major problem in extension throughout Africa is that of a disconnect between farmer resource levels and inflexible extension recommendations that tend to optimize biological yields and require high rates of purchased inputs (Chambers et al., 1989; Okali et al., 1994). For example, average fertilizer use on corn in Malawi is $<10 \mathrm{~kg} \cdot \mathrm{ha}^{-2}(8.9 \mathrm{lb} / \mathrm{acre})$ of nitrogen yet the official recommendation is for 10 -fold higher amounts of nitrogen (Malawi Ministry of Agriculture and Livestock Development, 1995). Blanket recommendations for fertilizer rates and corn management have been extensively revised to fit local market and production conditions, yet these more flexible recommendations have not been disseminated (Benson, 1997; Gilbert et al., 2002; Malawi Ministry of Agriculture and Livestock Development, 1995).

Extension workers in Malawi, and throughout sub-Saharan Africa, face a difficult task. Minimal support is available for the ambitious task of reaching smallholders throughout the country. Examples of collaboration across sectors in Malawi are presented here to show how extension can help farmers adapt information and link up with other partners, from processors to input suppliers.

\section{Horticulture extension in Malawi}

A history of the Malawi government shows a tremendous commitment by the government and the donor community to build and maintain the extension service, in the face of severe budget constraints. Extension, however, has focused primarily on the staple field crop in Malawi, corn, with minimal attention to horticultural crops. In particular, crops that are grown near the homestead have been almost completely neglected throughout Africa (Moris, 1991). This is surprising, given the importance of horticulture to export earnings, and to smallholder food security throughout sub-Saharan Africa. Yet $<10 \%$ of government extension staff in Malawi have horticulture experience, or training, beyond superficial exposure as a part of general agriculture coursework (Kwapata, 1999).

Training in horticulture was introduced to middle and senior level extension officers in the early 1970s as part of a general agricultural upgrading for Malawi extension (Kwapata, 1999). By 1980 there was one senior officer subject matter specialist responsible for horticulture in the government extension service. Specific horticultural courses were initiated at the Natural Resource College (a 2-year technical college) and as part of the BS degree training at Bunda College of Agriculture, University of Malawi in the 1980s. This produced extension staff with some exposure to horticulture, although it was still a small proportion of the entire extension work force. The training and visit (T and V) programmatic approach- 
es tended to dominate extension in the 1980s throughout sub-Saharan Africa, which relied on subject matter specialists who were charged with training extension workers who in turn presented information to contact farmers. There were few $\mathrm{T}$ and $\mathrm{V}$ related projects that targeted horticultural crops or invested in training of horticulture subject matter specialists (Amin and Stewart, 1994; Moris, 1991; Roberts, 1989).

In the 1990s horticulture became a specialization option for post graduate studies at Bunda College of Agriculture, University of Malawi (Kwapata, 1999). However, this does not mean that the Malawi government extension service has gained horticultural specialists as hiring has been suspended in recent years. Most graduates from the University of Malawi are now employed by the private agribusiness sector or by nongovernmental organizations (NGOs), not by the formal extension service.

The latest development in Malawi extension is the entry of NGOs into horticultural training for crop advisors, from the private and the public sectors. This includes training of front line staff with minimal educational backgrounds. Nongovernmental organizations such as World Vision and Concern Universal have started an internship and experiential learning program in cooperation with the Natural Resource College (J. Mapemba, personal communication). This provides intensive training in agriculture with a focus on horticulture. In addition, NGOs and private industry have produced horticultural short courses on crop management and post harvest treatment of novel crops (Table 2).

Until recently, NGOs and private industry were highly regulated and restricted in Malawi. The involvement of NGOs and agroindustry groups in outreach has grown rapidly, and it is now necessary to consider $\mathrm{NGO}$ and private industry activities along with government extension (Kwapata, 1999). Among these organizations there are major differences in goals, regional focus and methodology (Table 2). Private industry focuses on areas with favorable resources such as fertile soils, moderate climate, access to transportation and relatively well developed infrastructure. Farmers reached include those with more education and access to capital to invest in fertilizer and in improved seeds. NGOs also tend to be localized, but focus instead on areas with limited access to markets and transportation, and regions with high levels of malnutrition and poverty. The government extension service has the ambitious mandate to be present in every district in the country, and to reach all smallholder rural residents (Table 1). Recent experiences suggest that government extension staff tend to work with master farmers and well connected members of communities, whereas NGO staff frequently target poor farmers, widows and migrants (Mapemba, 2001; Snapp et al., 2002a).

Outreach methods also vary with the different sectors. Private industry tends to rely on market incentives that reward product quality, combined with training sessions and mobile crop advisors to extend technical information to producers (Toomey et al., 2000). NGOs on the other hand tend to focus on broad based training, to improve capacity among smallholder farmers through assertiveness training, improved gov- ernance and development of business skills (Mapemba, 2001). NGOs may also conduct training in production techniques and on-farm experimentation skills, to help farmers adapt information tolocal conditions. Government extension approaches have changed over time (Table 1 ). Training and visit was a popular extension method in the 1980s (Roberts, 1989), whereas adaptive trials and broad-based demonstrations of packages were widely used in the 1990s (Kumwenda et al., 1997; Okali et al., 1994). A participatory extension approach has been promoted recently in Southern and Eastern Africa (Hagmann et al., 1996; Kanyama-Phiri et al., 1998; Ramaru et al., 2000). Participatory extension is community based, where extension agents act as catalysts to promote local organizations and stakeholder meetings to prioritize problems and opportunities and empower clients, e.g., farmers, consumers, input suppliers and market buyers, to be engaged in the technology development and dissemination process. Although embraced by some, a survey indicated that extension staff from two districts in Malawi had significant doubts about the participatory extension approach and perceived it as expensive, time demanding and not sufficiently technically oriented (Snapp et al., 2002a).

One of the many challenges to building horticultural capacity in extension is the turnover of staff. A significant proportion of extension positions remain unfilled in Malawi - over $40 \%$ in some regions of the country. A review by Moris (1991) indicated that staff leave positions due to low pay, poor morale, lack of resources to conduct outreach, hierarchal organizational structures with

Table 1 Government extension organizational structures and outreach methodologies; examples from sub-Saharan Africa.

Government extension

Extension organizational structure

Multilayered, with six or more levels of management between the frontline staff and central office

Frontline staff limited in number with few resources, in comparison to the number of clients (ratio of farmers to extension agents frequently higher than 2000:1)

Outreach methods:

Training and visit (frontline staff expected to meet regularly with farmer groups from different regions)

Country-wide trials that demonstrate a package of improved, recommended practices (not always appropriate to farmer resource levels and not a flexible, incremental approach to adoption)

Participatory extension models that involve farmers as active decision makers are being experimented with in countries such as Kenya, Mali, Malawi, South Africa, Uganda, and Zimbabwe

Adoption model

Focus primarily on progressive, male farmers who are seen as the early adopters expected to lead the way for other farmers (this can lead to the neglect of groups with limited access to information and resources, especially the poorest farmers, new migrants to an area and to households led by females $)^{z}$

Contact with extension staff and demonstrations expected to impart technical knowledge

zThis is illustrated by a study of Malawi bean cropping systems (Ferguson, 1994). 
tremendous disparity and divisions by rank, as well as generally difficult conditions of service. In addition, the devastating effect of the HIV/AIDS epidemic cannot be underestimated (Qamar, 2001).

Limited budgets have made it difficult to retain and upgrade extension staff in Malawi. There is considerable competition among organizations for a relatively small pool of trained personnel. Yet at the same time cooperation exists, and NGOs and private industry are seen by many government extension officers as the primary means of obtaining advanced training, and for securing operating budgets for outreach activities (Table 2 ). In some cases extension workers participate fully with other organizations through temporary or permanent transfers (Mapemba, 2001).

Close collaboration across private and public sectors has a key role to play in improving access to information, training farmers and enhancing agricultural productivity. However, this can have high transaction costs, as indicated repeatedly by extension personnel in Malawi (Snapp et al., 2002a). Cooperation across organiza- tions requires coordination of efforts, frequent meetings and human capacity building as well as resources that are devolved to the local level, which does not always occur (Moris, 1991).

\section{Innovations in extension methods}

Extension faces many challenges in Malawi, not least is the considerable problem of reaching farmers with little formal education and poor access to media or communication channels (Table 1). Radio may be one of the most effective means of reaching a widely dispersed rural population with extension methods, particularly as cutbacks in extension staffing reach over $30 \%$ in some areas (Snapp and Heong, 2003). Role playing and acting is another form of engagement that may be particularly appropriate to an audience that varies in literacy skills. Drama is unique in its ability to facilitate community engagement with controversial subjects, where differing opinions can be voiced within the drama, to foster discussion. The combination of radio and drama has recently been promoted in Malawi, through a weekly drama series that addresses a wide range of topics, including agricultural prob- lems in a community setting (The Story Workshop, 2002). This organization also promotes community discussion of issues directly, by hosting radio debates such as a series of debates in Oct. 2000 that presented different views of how the horticultural industry is evolving in Malawi (Nhlane, 2000).

An exciting extension approach that uses mass media in a participatory mode has been pioneered in Asia. This is the use of radio and poster campaigns to challenge farmers to experiment on their own and test new integrated pest management techniques (Escalada et al., 1999). This approach has the advantage of reaching many farmers and engaging them in testing a recommendation or cultivar, on their own. However, this method may not translate directly to the Malawi context. Compared to Asia, smallholder farmers in sub-Saharan Africa have very limited purchasing power and food insecurity is high, which limits the ability of most farmers to try out new seeds or pest monitoring techniques. Further, formal education levels tend to be very low. This makes it difficult to communicate by radio complex ecological processes or integrated

Table 2. Description of organizations and activities involved in providing Malawi agricultural extension and outreach services.

\begin{tabular}{ll}
\hline & $\begin{array}{l}\text { Private } \\
\text { industry }\end{array}$ \\
\hline Locale & Localized-operating in areas with infrastructure and access to markets \\
Clientele & Entrepreneurial farmers, with more education and with access to more resources \\
Outreach methods used & Development of paprika industry: \\
& 1) Communicating market context, price and product quality information; \\
& 2) Training in best production practices \\
Challenges to achieving outreach & 1) Primarily local impact; \\
& 2) Relevance restricted to more developed areas; \\
3) Market may be limited in scope & Private industry, NGOs and government extension working together to develop pigeon pea commercialization. \\
Collaborative approach & Extension of improved cultivars and management practices adapted to on-farm conditions and market quality standards
\end{tabular}

Table 3. Innovations to catalyze a revitalization and expansion of pigeon pea production and marketing systems in Malawi. Table adapted from Snapp et al., 2003.

Research and production

Traditional system

Production system/variety innovation

Marketing innovations and new institutional relationships
Geographically dispersed smallholders produce a corn/pigeon pea intercrop with traditional cultivars that have limited yield potential. Low quality product.

1) Government extension, nongovernmental organizations (NGOs) and university researchers collaborate to test performance of new cultivars with farmers, linked to processor evaluation of cultivars

2) A range of cropping patterns tested, including peanut/pigeon pea and tomato/pigeon pea intercrop systems, which offer improved profitability

Farmers participate in forming organizations and training in technical production and business skills. 1) Leverage stable, higher product prices through consistent production of quantity and quality;

2) Gain access to market information on regional prices, quality and product opportunities.

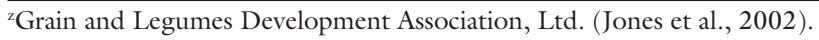


pest management practices (Snapp and Heong, 2003).

Human capacity building of the rural population may be a necessary first step for effective extension in Malawi, and other under developed nations. Yet considerable investment would be required to build literacy, numeracy, business knowledge and understanding of ecological principles among smallholders. Farmer field schools and participatory extension are strategies that are being promoted to build local human resource capacity (Braun et al., 2000). These are being tried out on a small scale in southern Africa countries (Hagmann et al., 1996; Ramaru et al., 2000; Kanyama-Phiri et al., 1998). However, an important question remains: who is going to pay for this? Identifying support for a country-wide effort in capacity building and nonformal education is not an easy task. It would require a tremendous investment to help a significant number of smallholders understand ecological principles and how to apply the principles to improve farm management (Braun et al., 2000).

In addition to building capacity among farmers, recent experiences in
Malawi indicate the need for extension to help catalyze market opportunities and access to inputs. These are components of participatory extension that cannot be neglected if farmers are to benefit from extension advice. This view is supported by a survey of farmers involved in participatory research and extension to promote legume adoption in central and southern Malawi (Snapp et al., 2002b). As much as farmers appreciated technical training and opportunities to try new legumes, concerns were repeatedly raised about gaining access to markets.

\section{Extension as a catalyst for new crop opportunities}

Dissemination of technical advice has been a pillar of extension's mandate in Malawi, as elsewhere in Africa (Roberts, 1989). In some areas extension staff have until recently operated in almost a bubble, handing out advice in a top-down and coercive manner, in what has been called the colonial agricultural officer syndrome (Moris, 1991). From this perspective farmers are frequently seen as too conservative and apathetic to adopt modern agricultural advice (Chambers et al.,
1989). Yet this is changing, as many extension staff and NGO farm advisors are becoming aware that farmers are not resistant to recommendations that are appropriate to local resources and priorities. Smallholder farmers are experimenting on their own, although the levels of inputs used may be at very low levels, and technical advice needs to take this into account (Rohrbach and Okwach, 1998).

Recently, extension has begun to take into account more than production goals, considering the wide-range of livelihood strategies that farmers pursue. Livelihood strategies include different avenues used to insure food security and farm survival, such as offfarm income generation, working for neighbors, barter and gathering wild products. Thus extension staff are required to address diverse goals and act as catalyst, rather than focusing on transfer of technologies (McDougall and Braun, 2003). Farmers express the need for improved access to market information and advice about how to meet quality requirements, as well as cost-effective means of using inputs (Snapp et al., 2002b). A dynamic, whole systems approach focuses on

\author{
Nongovernmental \\ organization (NGO) \\ Localized-operating in areas with few resources and high poverty levels \\ Limited resource farmers, especially: female-headed households and families with children at risk \\ Participatory extension to improve soil and crop management: \\ 1) Empowerment and training in business, agriculture and experimentation; \\ 2) NGO catalyze farmer-led adaptive trials \\ 1) Primarily local impact; \\ 2) Requires expensive, long-term investments in human capacity building
}

\section{Extension} system

Country-wide - represented in every district

All smallholder farmers and rural residents in Malawi

\footnotetext{
1) Training and visiting approach to systematically reach farmers in each extension district;

2) Country-wide demonstration trials to verify and extend new recommendations

1) Minimal impact anywhere;

2) Relevance of recommendations and technologies have been questioned
}

Extension

Extension focus is on corn and other crops, not pigeon pea

Occasional demonstrations of new pigeon pea cultivars and pesticide application techniques

1) Extension brings together processors, traders and farmers to develop seed systems and access to new cultivars

2) Extension promotes farmers experimenting with and testing new cropping patterns and production systems with improved cultivars
Market systems

Local and interregional traders purchase pigeon pea products at dispersed

locations, sell to processors and exporters to process products for market

Processors evaluate new cultivars. In Malawi, pigeon pea cultivar ICEAP 00040 was identified as promising due to high quality processing traits including ease of dehulling, light color and large size

Processors and exporters in Malawi formed GALDAL ${ }^{z}$ to develop the industry by

Extension, NGOs and private industry invest in farmer skill building and formation of farmer-marketer organizations.

1) Develop farmer business skills, organizations and links to larger buyers

2) Improve communication among all parties.

2) Assisting in farmer training and hire farm advisors

3) Developing new markets 
strategies that address production goals while at the same time taking into account other farm enterprises, minimizing risk and addressing the vulnerabilities of unstable markets and drought-prone climates (Rohrbach and Okwach, 1998). Examples of dynamic systems approaches to research and extension have been developed in the US Great Plains (Tanaka et al., 2002) and for organic farming, in North Carolina (Creamer et al., 2000).

Recent experiences with paprika, a new crop in Malawi, indicate how a whole systems approach can work. New opportunities have opened up in the region with recently liberalized markets. There is a global market for a paprika dried product as a natural red food coloring agent. In selected regions of Malawi, extension staff have helped private industry organizations, such as Cheetah Paprika, Inc. (Lilongwe, Malawi), to combine efforts with local traders, and international NGOs, to build local capacity to become a reliable source of high quality paprika. Paprika exporters have subsidized training and teamed up with extension advisors to bring crop advice to smallholders, along with improved access to inputs (Toomey et al., 2000). Farmers had a strong incentive for learning the new technology and being part of this market opportunity. NGOs and public sector extension worked together with Cheetah Paprika staff, to help reduce risks and build the industry by helping organize activities and training in crop management and on-farm post harvest processing.

Quality of product is as important as quantity for paprika sales so it has been crucial for the nascent industry to develop and disseminate quality criteria and preferential payment information to farmers, combined with training in how to meet these goals. Cheetah Paprika has also pursued a proactive strategy with buyers, producing a high quality product and demanding a premium price. This stands in contrast with another agribusiness company in Malawi, Press Agriculture, which made minimal investments in training and extension for farmers and was not able to negotiate a higher price from Spanish paprika buyers. Press Agriculture recently abandoned involvement in paprika production, purchasing and exportation (Toomey et al., 2000).

Only in selected areas, such as the mid-altitude region in central Malawi, has the paprika market opportunity been able to succeed. These are areas with access to infrastructure and where transport costs are relatively low. As illustrated in Table 2, the relative strengths and weaknesses of different extension actors are highlighted by the paprika experience. Private sector efforts tend to be concentrated in areas where access to government extension is already strong. It remains a challenge to reach the majority of farmers who are more dispersed. This is not always considered by advocates of outsourcing public sector extension responsibilities.

Revitalizing the pigeon pea industry in Malawi is another example where cooperation is being attempted across diverse organizations, with intermittent progress (Jones et al., 2000). Pigeon pea is a multi-use crop that can be used to meet soil fertility and food security needs, as well as sold for use as an immature pod vegetable or as a grain crop grown for export (Snapp et al., 2003). The Malawi pigeon pea industry is at a critical stage: the traditional production and dissemination systems are breaking down due to high transaction costs with dispersed traders buying small amounts of low quality products from traditional cultivars grown in intercrop systems in dispersed pockets of southern Malawi (Table 3 ). Recent developments include a new organization, the Grain and Legumes Development Association Limited, formed by processors to promote the industry and identify new markets (Jones et al., 2002). However, there has been sporadic involvement by extension and NGOs in helping organize farmers, conduct training or promote improved pigeon pea cultivars, such as ICEAP 00040 (Table 3).

The paprika experience is not directly applicable to pigeon pea. Yet there are similarities, and collaborative effort across private and public sectors could address the need to improve the quality of pigeon pea products and enhance farmer access to training and improved cultivars (Snapp et al., 2003). Innovative, cross-organizational strategies for pigeon pea extension services could help rebuild Malawi's reputation as a pigeon pea exporter, while at the same time building local markets and subsistence use of this crop.

\section{Conclusions}

There are considerable challenges posed by limited resources and bureaucratic 'stasis' in African extension services. Conventional training and visit approaches, and demonstrations of technical packages, have tended to be rigidly applied, with minimal transfer of information to smallholders. Yet, there are pockets of remarkable innovation in Malawi. This paper illustrates a range of extension approaches and opportunities for further collaboration. Extension efforts have helped catalyze new cropping opportunities in paprika and pigeon pea through collaboration with nongovernmental organizations, private industry and government extension. In some areas a shift has occurred from a focus on farmers as recipients of recommendations to farmers as entrepreneurs and decision makers. One caveat is that successful examples of outreach have tended to be highly localized, involving primarily farmers with access to markets. It remains a much bigger challenge to reach the most disadvantaged farmers, especially those that are geographically dispersed with limited access to infrastructure.

\section{Literature cited}

Amin, A.H. and B.R. Stewart. 1994. Training and visit extension program outcomes in Ninia governorate. Egypt. J. Agr. Educ. 35:30-34.

Benson, T. D. 1997. Spatial and temporal variation in fertilizer recommendations for maize grown by smallholders in Malawi, p. 135-144. In: T.D. Benson (ed.). Maize Commodity Team Annual Report 1995/ 1996. Min. Agr. Irr., Dept. Agr. Res., Lilongwe, Malawi.

Benson, T.D. 2002. Malawi: An atlas of social statistics. National Statistical Office, Government of Malawi and International Food and Policy Research Institute, Washington, D.C.

Braun, A.R., G. Thiele, and M. Fernandez. 2000. Farmer field schools and local agricultural research committees: complementary platforms for integrated decision-making in sustainable agriculture. Agr. Res. Ext. Network Paper 105. Overseas Development Inst., Chatham, U.K.

Chambers, R., A. Pacey, and L.A. Thrupp. 1989. Farmers first: Farmer innovation and agricultural research. Intermediate Technol. Publ., London.

Creamer, N.G., K.R. Baldwin and F.J. Louws. 2000. A training series for cooperative extension agents on organic farming systems. HortTechnology 10:675-681. 
Escalada, M.M., K.L. Heong, N.H. Huan, and V. Mai. 1999. Communications and behavior change in rice farmers' pest management: The case of using mass media in Vietnam. J. Applied Commun. 83:7-26.

Ferguson, A. 1994. Gendered science: A critique of agricultural development. Amer. Anthropol. 96:540-552.

Gilbert, R.A., M.K. Komwa, T.D. Benson, and W.D. Sakala. 2002. A comparison of best-bet soil fertility technologies for maize grown by Malawian smallholders: A research report of the results of the nationwide 1998/99 and 1999/2000 on-farm cropping system verification trial by Action Group I, Maize Productivity Task Force. Govt. Malawi Press, Lilongwe, Malawi.

Hagmann, J., E. Chuma, and K. Murwira. 1996. Improving the output of agricultural extension and research through participatory innovation development and extension; experiences from Zimbabwe. Euro. J. Agr. Educ. Ext. 2:15-23.

Jones, R., A. Likoswe, and H.A. Freeman. 2000. Improving poor farmers' access to technologies and markets for pigeonpea in Malawi, p. 150-157. In: J.M. Ritchie (ed.). Integrated crop management research in Malawi: Developing technologies with farmers. Proc. final workshop of the farming systems integrated pest management project, Nat. Resour. Inst., Chatham, U.K.

Jones, R., A. Likoswe, and H.A. Freeman. 2002. Improving the access of small farmers in Eastern and Southern Africa to global pigeonpea markets. Agr. Res. Ext. Network Paper 120. Overseas Dev. Inst., Chatham, U.K.

Kanyama-Phiri, G.Y., S.S. Snapp and S. Minae. 1998. Partnership with Malawian farmers to develop organic matter technologies. Outlook Agr. 27:167-175.

Kwapata, M.B. 1999. The history of horticulture in Malawi, p. 4-6. Horticulture in Malawi. vol. 2. Govt. Malawi Press, Lilongwe, Malawi.

Kumwenda, J.D.T., S. Waddington, S.S. Snapp, R.B. Jones, and M.J. Blackie. 1997. Soil fertility management in the smallholder maize-based cropping systems of Eastern and Southern Africa, p. 153-172. In: D. Byerlee and C.K. Eisher (eds.). The emerging maize revolution. Lynne Publ., Boulder, Colo.

Malawi Ministry of Agriculture and Livestock Development. 1995. Guide to Agriculture Production. Govt. Malawi Press, Lilongwe, Malawi.

Mapemba, J. 2001. Dedza, Malawi participatory research and extension, p. 41-52. In: S.J. Twomlow and B. Ncube (eds.). Improving soil management options for women farmers in Malawi and Zimbabwe. International Crops Research Institute for the Semi-Arid Tropics, Bulawayo, Zimbabwe.

McDougall, C. and A. Braun. 2003. Navigating complexity, diversity and dynamism: reflections on research for natural resource management, p. 20-47. In: B. Pound, S.S. Snapp, C. McDougall, and A. Braun (eds.). Uniting Science and Participation: Managing natural resources for sustainable livelihoods. Earthscan Publ., London.

Moris, J. 1991. Extension alternatives in tropical Africa. Overseas Dev. Inst., London.

Nhlane, S. 2000. Here they come again: Story workshop educational trust's second radio debate on agriculture. The Nation 29 Sept. 2000.

Okali, C., J.E. Sumberg, and K.C. Reddy. 1994. Unpacking a technical package: Flexible messages for dynamic situations. Expt. Agr. 30:299-310.

Qamar, M.K. 2001. The HIV/AIDS epidemic: an unusual challenge to agricultural extension services in sub-Saharan Africa. J. Agr. Educ. Ext. 8:1-11.

Ramaru, J., Z. Mamabolo, and J. Lekgoro. 2000. Improving soil fertility management in South Africa: Learning through participatory extension approaches. Managing Africa's Soils, Working Paper No. 19. Intl. Inst. Environ. Dev., London p. 17.

Roberts, N. 1989. The World Bank and the training and visit systems in East Africa, p. 10-65. In: N. Roberts (ed.)
Agricultural extension in Africa: A World Bank Symposium. The World Bank, Wash., D.C.

Rohrbach, D.D. and G.E. Okwach. 1998. Modeling crop performance or cropping decisions, p. 47-58 In: Risk management for maize farmers in drought-prone areas of southern Africa. Intl. Crops Res. Inst. for the Semi-Arid Tropics (ICRISAT) and International Maize and Wheat Improvement Ctr. (CIMMYT), Mexico, D.F.

Snapp, S.S. and K.L. Heong. 2003. Scaling up: participatory research and extension to reach more farmers, p. 67-87. In: B. Pound, S.S. Snapp, C. McDougall, and A. Braun (eds.). Uniting Science and Participation: Managing natural resources for sustainable livelihoods. Earthscan Publ., London.

Snapp, S.S., G. Kanyama-Phiri, B. Kamanga, R. Gilbert, and K. Wellard. 2002a. Farmer and researcher partnerships in $\mathrm{Ma}$ lawi: developing soil fertility technologies for the near-term and far-term. Expt. Agr. 38:411-431

Snapp, S.S., D.D. Rohrbach, F. Simtowe, and H.A. Freeman. 2002b. Sustainable soil management options for Malawi: can smallholder farmers grow more legumes? Agr. Ecosystem Environ. 91:159-174.

Snapp, S.S., R.B. Jones, E.M. Minja, J. Rusike, and S.N. Silim. 2003. Pigeon pea for Africa: A versatile vegetable — and more. HortScience (in press).

Tanaka, D.L., J.M. Krupinsky, M.A. Liebig, S.D. Merrill, R.E. Ries, J.R. Hendrickson, H.A. Johnson, and J.D. Hanson. 2002. Dynamic cropping systems: An adaptable approach to crop production in the Great Plains. Agron. J. 94:957-961.

The Story Workshop. 2002. The Story Workshop. 9 Sept. 2003. <http:// www.storyworkshop.org/weare.html>.

Toomey, D.C., P.A. Sterns, and C. Jumbe. 2000. The impact of improved grades and standards on the export potential of targeted commodities in Malawi. Mich. State Univ. U.S.Agency Econ. Dev., PFID-F\&V Rpt. 2. 9Sept. 2003. <http://www.pfid.msu.edu/ pdf_files/Malawi_Final_Report.pdf>. 